\title{
US calls for more restrictions on e-cigarettes for youth
}

Cite as: CMAJ 2017 January 23;189:E131. doi: 10.1503/cmaj.109-5374

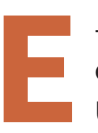
-cigarette use is "a major health concern" among youth, says the United States surgeon general in a call to action.

In a new report on e-cigarette use among youth and young adults, Surgeon General Vivek H. Murthy states that youth are in danger of possible addiction and potential long-term harm to brain development and respiratory health.

The report calls for incorporating e-cigarettes into smoke-free policies, regulating e-cigarette marketing and increasing research and public education. Murthy also unveiled an online educational site, with resources for youth and parents. In May 2016, the US banned the sale of e-cigarettes to anyone under the age of 18 .

E-cigarette use among American youth has surpassed that of cigarettes, increasing 900\% from 2011-14, according to the report. About one in six US high school students say they've used an e-cigarette in the past year.

Murthy is adamant about the need for action. "Although we continue to learn more about e-cigarettes with each passing day, we currently know enough to take action to protect our nation's young people from being harmed by these products," he stated in the report.

Meanwhile, Canada's Parliament has yet to accept March 2015 recommendations on e-cigarettes. Provinces have been left to legislate their own controls, resulting in patchwork governance, and five regions - Alberta, Saskatchewan, Yukon, Northwest Territories and Nunavut - have no regulations at all.

As the law currently stands, the Canadian Society of Respiratory Therapists says

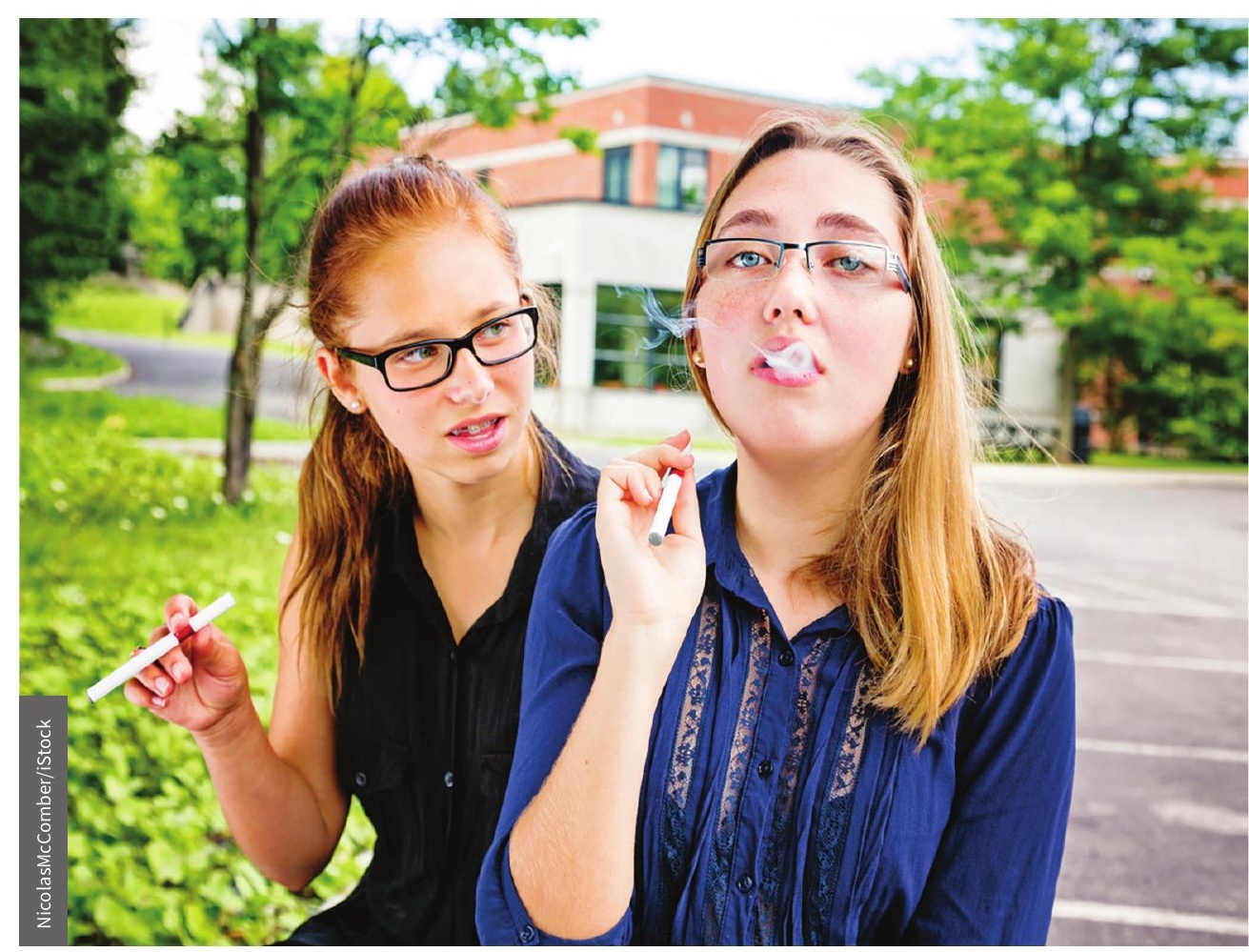

About one in six US high school students say they've used an e-cigarette in the past year.

e-cigarettes are accessible to any age group. "They're using e-cigarettes and then they're progressing on to other forms of inhaled substances," says Past President Jessie Cox. "We do know that any kind of inhaled particle at all can cause respiratory illness."

Canada's Standing Committee on Health issued a report in March 2015 with 14 recommendations on restricting the sale and use of e-cigarettes, including banning the sale to minors nationwide, and banning flavourings, which are attractive to youth. Bill S-5, the new Tobacco and Vaping
Products Act which addresses the report's recommendations, passed second reading in the Senate Dec. 13 and is now headed to committee.

The negative effects of e-cigarettes have been emphasized by Murthy and others, but research indicates that some people use e-cigarettes as a smoking cessation tool. A recent CMAJ study reported that $5.8 \%$ of Grade 9 youth in Niagara, Ontario, said they used e-cigarettes to reduce or quit cigarette smoking.

Jay Rankin, CMAJ 